\title{
Erratum - Assessing the effects of climate and volcanism on diatom and chironomid assemblages in an Andean lake near Quito, Ecuador
}

\author{
Neal MICHELUTTI, ${ }^{*}$ Jillian L. LEMMEN, ${ }^{1}$ Colin A. COOKE, ${ }^{2}$ William O. HOBBS,${ }^{3}$ Alexander P. WOLFE, ${ }^{4}$ \\ Joshua KUREK, ${ }^{1}$ John P. SMOL ${ }^{1}$ \\ ${ }^{1}$ Paleoecological Environmental Assessment and Research Lab (PEARL), Department of Biology, Queen's University, Kingston, \\ Ontario, K7L 3N6, Canada; ' $D$ Department of Environment and Sustainable Resource Development, Edmonton, AB T6G 2E9, Canada, \\ Government of Alberta, Edmonton, AB T5K 2M4, Canada; ${ }^{3}$ Washington State Department of Ecology, Olympia, WA, 98504-7600, \\ USA; ${ }^{4}$ Department of Biological Sciences, University of Alberta, Canada \\ *Corresponding author: nm37@queensu.ca
}

Received: February 2016. Accepted: February 2016.

This corrects the article entitled 'Assessing the effects of climate and volcanism on diatom and chironomid assemblages in an Andean lake near Quito, Ecuador' by the authors Neal Michelutti, Jillian L. Lemmen, Colin A. Cooke, William O. Hobbs, Alexander P. Wolfe, Joshua Kurek, John P. Smol, published with DOI 10.4081/jlimnol.2015.1323.

The map in Fig. 1 was incorrectly labelled and the correct version of Fig. 1 is presented below.

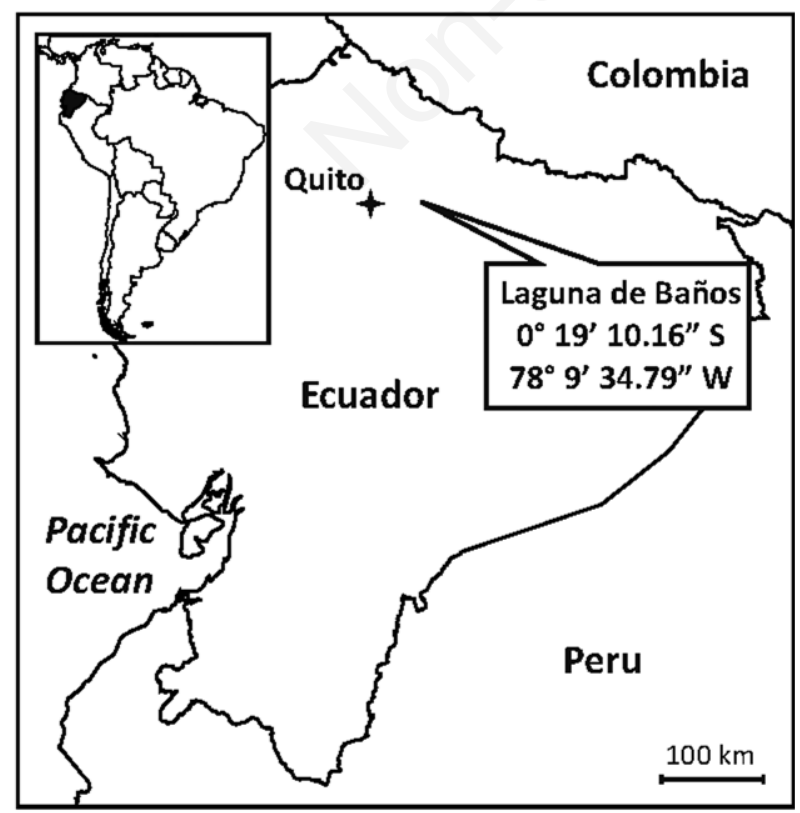

Fig. 1. Map showing the location of Laguna Baños in Ecuador. 